Cite this: Analyst, 2013, 138, 3638

Received 4th January 2013

Accepted 8th May 2013

DOI: $10.1039 /$ c3an00024a

\section{A rhodamine based "turn-on" chemodosimeter for monitoring gold ions in synthetic samples and living cells $\uparrow$}

\author{
Mustafa Emrullahoğlu, ${ }^{*}$ Erman Karakuş and Muhammed Üçüncü
}

\begin{abstract}
A rhodamine-based fluorescent probe, functionalized with an alkyne moiety, shows highly selective recognition towards $\mathrm{Au}(\mathrm{I})$ and $\mathrm{Au}(\mathrm{III})$ ions over other metal ions. Probe 1 is successfully employed for the determination of residual gold species in synthetic samples and monitoring the accumulation of gold ions in living cells.
\end{abstract}

The chemistry of gold has attracted special attention recently. ${ }^{\mathbf{1}}$ Gold ions and their complexes display remarkable alkynophilic properties and are recognized as catalysts for chemical transformations. ${ }^{1}$ Besides their catalytic properties, gold species have interesting biological properties and uses. They play important roles in biological systems and often have significant impacts on human health. For example, gold-based drugs have long been used in the treatment of rheumatoid arthritis and other autoimmune diseases. ${ }^{2}$ In addition, gold nanoparticles function as carriers for drug and gene delivery systems. ${ }^{3}$ Gold ions, on the other hand, are potentially toxic to humans. Because of their reactive nature, ionic gold species can interact with proteins, DNA and other biomolecules and disturb a series of cellular processes, leading to serious health problems. ${ }^{4}$

The number of synthetic processes utilizing gold catalysts is continuously increasing. It is highly possible that the chemicals synthesized through gold catalysis may still contain impurities of the catalyst after purification. Metal impurities that exist in any steps of a synthetic process may interfere with further steps. Due to toxicity and the interference effects arising from gold species, simple and reliable detection methods for gold species with high selectivity are highly desirable.

In recent years, great effort has gone into the development of fluorescent sensing methods because they are highly effective in determining metal species. ${ }^{5}$ The strategy of designing a metal

Department of Chemistry, Faculty of Science, Izmir Institute of Technology (IZTECH), Urla 35430, Izmir, Turkey. E-mail: mustafaemrullahoglu@iyte.edu.tr; Fax: +90 232 750 7509; Tel: +902327507610

$\dagger$ Electronic supplementary information (ESI) available: Synthesis and characterization of probe $\mathbf{1}$, and all data for UV-Vis and fluorescence titrations. See DOI: $10.1039 / \mathrm{c} 3 \mathrm{an} 00024 \mathrm{a}$ specific fluorescent probe is based on the introduction of a metal binding or reactive unit to a fluorophore that translates the binding event to a fluorescence signal upon interaction with metal species. Alkynes, because of their strong binding affinity to alkynophilic metals, appear to be suitable binding platforms for gold ions. Therefore, introducing a reactive alkyne moiety to the fluorophore could provide an efficient route to developing a gold specific fluorescent probe. In this regard, several "turn-on" type fluorescent probes for gold ions based on rhodamine, ${ }^{6}$ fluorescein ${ }^{7}$ and BODIPY ${ }^{8}$ dyes have been successfully designed and described in the literature. ${ }^{9}$

Research on the development of fluorescent probes for gold species is gradually gaining interest. However, there are several shortcomings such as cross-sensitivity toward other metal cations, low water solubility, slow response, low fluorescence enhancement and cytotoxicity which impede the optimum performance of those fluorescent sensing systems. It is apparent that there is a need to design new fluorescent probes for gold ions which can overcome these limitations.

Herein, we report the synthesis and application of a novel gold ion selective fluorescent probe (1) that operates through a chemical reaction triggered by gold ions. Our goal in this work was to detect and quantify residual gold species in synthetic samples prepared via gold catalysis and to monitor the accumulation of gold ions in living cells by employing the fluorescent probe 1 developed in this study (Scheme 1).

The rhodamine derivative (1), which contains a reactive alkyne moiety highly specific to $\mathrm{Au}^{+}$and $\mathrm{Au}^{3+}$ ions, was synthesized by reacting rhodamine-B hydrazide with 2-alkynylbenzaldehyde in ethanol at reflux temperature in a yield of $c a .70 \%{ }^{10}$

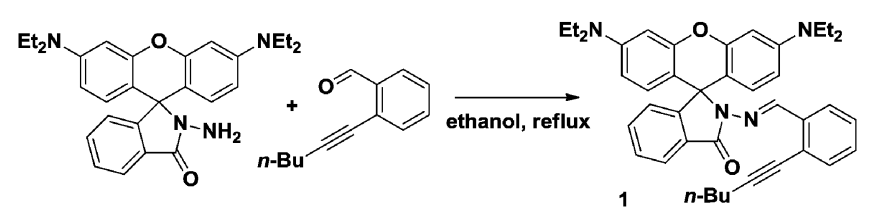

Scheme 1 Synthesis of Probe 1. 
We commenced our investigation by first examining the reaction media. Considering that probe $\mathbf{1}$ is not completely water soluble we screened various combinations of solvents including EtOH- $\mathrm{H}_{2} \mathrm{O}, \mathrm{CH}_{3} \mathrm{CN}-\mathrm{H}_{2} \mathrm{O}$ and DMSO- $\mathrm{H}_{2} \mathrm{O}$. A combination of $\mathrm{CH}_{3} \mathrm{CN}-\mathrm{H}_{2} \mathrm{O}(1: 1, \mathrm{v} / \mathrm{v})$ proved to be highly efficient for the sensing process. Moreover, we observed that an increase in the ratio of water resulted in a dramatic decrease in the fluorescence intensity which might be due to the deactivation of the catalyst species (Fig. S8†).

We further investigated the emission responses of probe $\mathbf{1}$ toward $\mathrm{Au}^{3+}$ at various $\mathrm{pH}$ conditions. As shown in Fig. $\mathrm{S} 2, \dagger$ probe 1 showed strong fluorescence intensity changes in the presence of $\mathrm{Au}^{3+}$ at $\mathrm{pH}$ 6-8. However, a gradual decline in the fluorescence intensity was observed at $\mathrm{pH}>8$ (Fig. S9 $\dagger$ ). Thus, a reaction medium buffered to $\mathrm{pH} 7.0$ was chosen for the purpose of physiological application.

As expected, the probe 1 was colorless in solution $\left(\mathrm{CH}_{3} \mathrm{CN}-\right.$ HEPES $(1: 1, \mathrm{v} / \mathrm{v})(\mathrm{pH}=7.0))$, showed no absorption in the visible region, and was nonfluorescent, indicating that the spirocyclic form of the dye was predominant. However, upon the direct addition of $\mathrm{AuCl}_{3}(60 \mu \mathrm{M}, 3$ equivalents with respect to probe 1), the colorless and nonfluorescent solution immediately became pink in color and started to fluoresce under UV light. The addition of $\mathrm{Au}^{3+}$ led to the appearance of a new strong absorption band centered at $556 \mathrm{~nm}$ and a strong fluorescence band at $580 \mathrm{~nm}$, which was attributed to the delocalized xanthene moiety of rhodamines. ${ }^{\mathbf{1 0}}$

The titration of $\mathrm{AuCl}_{3}$ into probe 1 gave a strong absorbance and fluorescence enhancement with the increase of the $\mathrm{Au}^{3+}$ concentrations (Fig. 1). The fluorescence titration profile of probe 1 with $\mathrm{Au}^{3+}$ showed a linear relationship for a concentration range of $1-100 \mu \mathrm{M}$, indicating the suitability of probe 1 for quantitative analysis. The detection limit was determined to be $0.6 \mathrm{ppm}(S / N>3) .{ }^{\mathbf{1 0}}$ The enhancement of emission intensity ( $>200$ fold) became saturated with the addition of $100 \mu \mathrm{M}$ of $\mathrm{Au}^{3+}$. Even though the spectroscopic response of probe 1 was quite fast $(<1 \mathrm{~min})$, the complete saturation of the signal intensity was observed after $60 \mathrm{~min}$ (Fig. S2 $\dagger$ ).

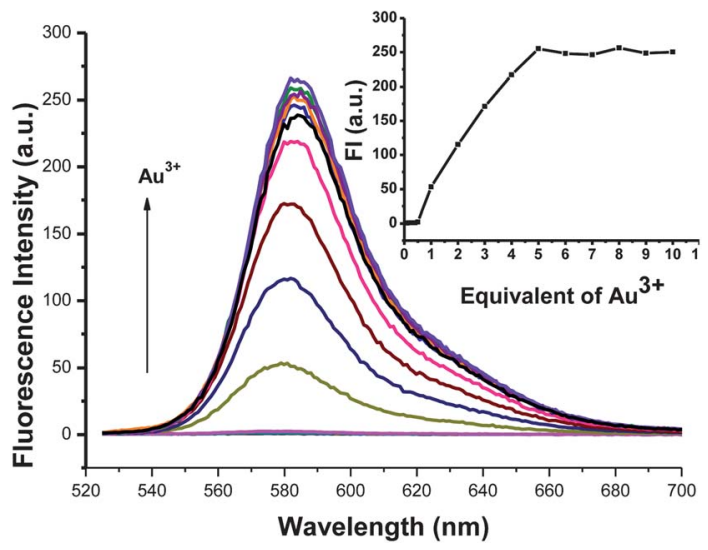

Fig. 1 Emission titration curve of probe $1(20 \mu \mathrm{M})$ and $\mathrm{Au}^{3+}(0-200 \mu \mathrm{M}, 0-10$ equiv.) in $1: 1 \mathrm{CH}_{3} \mathrm{CN}-\mathrm{HEPES}$ buffer at $\mathrm{pH} 7.0$; Inset: plot of fluorescence intensity depending on the number of equivalents of $\mathrm{Au}^{3+}$.
It was important to rule out the possible involvement of other alkynophilic metals in the sensing process. Therefore, the titration of probe $\mathbf{1}$ with various other metal ions was carried out under the same sensing conditions. To our delight, related alkynophilic metals such as $\mathrm{Ag}^{+}, \mathrm{Ni}^{2+}, \mathrm{Pd}^{2+}, \mathrm{Co}^{2+}, \mathrm{Hg}^{2+}$ and other metals including $\mathrm{Li}^{+}, \mathrm{Na}^{+}, \mathrm{K}^{+}, \mathrm{Ba}^{2+}, \mathrm{Ca}^{2+}, \mathrm{Cd}^{2+}, \mathrm{Mg}^{2+}, \mathrm{Mn}^{2+}, \mathrm{Zn}^{2+}$, $\mathrm{Pb}^{2+}, \mathrm{Cu}^{2+}, \mathrm{Cr}^{3+}, \mathrm{Fe}^{3+}$ did not trigger any ring opening reaction to give a spectroscopic response. As displayed in Fig. 2, only the addition of $\mathrm{Au}^{3+}$ and, to a lesser extent the addition of $\mathrm{Au}^{+}$ resulted in an enhancement of fluorescence at $580 \mathrm{~nm}$ (absorbance at $556 \mathrm{~nm}$ ), which obviously implied the high selectivity of probe 1 to gold ions and indicated a possible stronger interaction between the more highly charged $\mathrm{Au}^{3+}$ and the alkyne unit compared to $\mathrm{Au}^{+}$. Moreover, no significant color changes in probe solution were observed with the addition of other metal ions.

We further explored the fluorescence response of probe $\mathbf{1}$ toward $\mathrm{Au}^{3+}$ in the presence of the other metal ions in order to assess possible interferences by metal ions. As shown in Fig. S6, $\uparrow$ the tested metal ions displayed no interference with the detection of gold ions.

The overall sensing process was suggested to be reactionbased and irreversible. In order to prove this argument, an excess amount of cyanide ion $\left(\mathrm{KCN}\right.$ or $\left.\mathrm{Bu}_{4} \mathrm{NCN}(100 \mu \mathrm{M})\right)$ was subjected to the colored and fluorescent $\mathrm{Au}^{3+}$ containing probe 1 solutions. There was no change either in absorbance or fluorescence intensity after the addition of the cyanide source, which indicates that the sensing process is irreversible. Obviously, probe 1 operates through an irreversible chemical reaction and thus can be classified as a chemodosimeter.

Rhodamine derivative (3) lacking an alkyne moiety was prepared as a control probe by reacting rhodamine B hydrazide with benzaldehyde. ${ }^{11}$ Under the same sensing conditions no spectroscopic changes were observed upon the addition of $\mathrm{Au}^{3+}$ to probe 3 . This result clearly indicated that the alkyne moiety available on the probe structure plays a vital role in the signaling process. In other words, the signaling event was directly related to the activation of the alkyne unit by gold ions.

In order to get an insight into the sensing mechanism we decided to isolate all possible products formed by treating

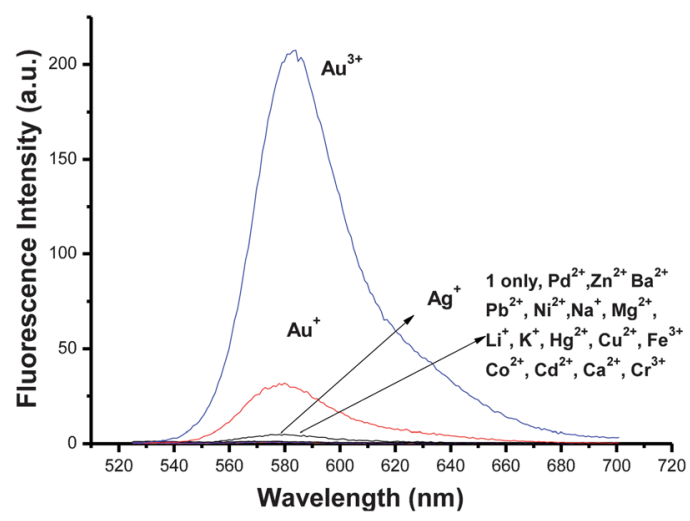

Fig. 2 Fluorescence intensities of probe $1(20 \mu \mathrm{M})$ in $1: 1 \mathrm{CH}_{3} \mathrm{CN}-\mathrm{HEPES}$ buffer at $\mathrm{pH}=7.0$ emission at $580 \mathrm{~nm}\left(\lambda_{\text {ex }}: 500 \mathrm{~nm}\right)$ : in the presence of metal ions $(100 \mu \mathrm{M})$. All data were taken after $60 \mathrm{~min}$. 

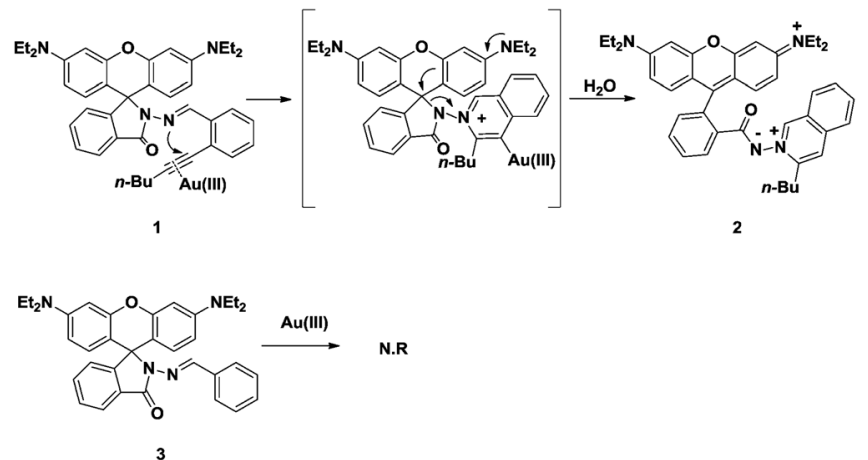

N.R

Scheme 2 Proposed mechanism.

probe 1 with $\mathrm{AuCl}_{3}$. This reaction afforded quantitatively one product as identified by TLC. The crude product was successfully purified by flash column chromatography and the structure of the product (2) was confirmed by ${ }^{1} \mathrm{H}-\mathrm{NMR},{ }^{13} \mathrm{C}-\mathrm{NMR}$ and mass spectroscopy analysis (MALDI-TOF-TOF and ESI-TOF). ${ }^{10}$ Based on the structure of the isolated product, we suggest that the sensing event should proceed through a gold-promoted intramolecular cyclization that causes the ring opening reaction to generate the highly fluorescent isoquinoline rhodamine derivative (2) (Scheme 2). The intramolecular cyclization of $N^{\prime}-2$ (alkynylbenzylidene) hydrazide to isoquinoline $N$-imine was previously investigated by others. Our proposed mechanism for the product formation is consistent with those reported. ${ }^{\mathbf{1 2}}$

To determine whether probe $\mathbf{1}$ could be applied to monitoring residual $\mathrm{Au}^{3+}$ ions in a synthetic end-product, we prepared oxazole 5 by treating propargylic amide 4 with $\mathrm{AuCl}_{3}$ following a previously described procedure (Scheme S3†). ${ }^{13}$ The resulting crude product was divided into four portions, and each portion was handled in different ways. In order to remove all gold residues from the crude product, the first portion was extracted with water and diethyl ether, the second portion was purified through a pad of silica gel, the third portion through a pad of Celite and the fourth portion through a pad of basic alumina $\left(\mathrm{Al}_{2} \mathrm{O}_{3}\right)$ (eluent: hexane-EtOAc). Subsequently, each purified sample $(2.0 \mathrm{mg})$ was sequentially subjected to the solutions of probe $1\left(20 \mu \mathrm{M}\right.$ in $1: 1 \mathrm{CH}_{3} \mathrm{CN}-\mathrm{HEPES}$, at $\mathrm{pH}=$ 7.0). We observed a distinct change in color and fluorescence in the sample solution isolated from the first three portions, whereas no color and fluorescence change was observed in the sample solution that was purified via $\mathrm{Al}_{2} \mathrm{O}_{3}$ column chromatography. The gold content in the sample purified through a silica pad was measured to be $5.90 \times 10^{-7} \mathrm{~mol} \mathrm{mg}^{-1}$ based on a standard calibration curve. The measured value was consistent with that obtained by inductively coupled plasma-mass spectrometry (ICP-MS) analysis $\left(6.27 \times 10^{-7} \mathrm{~mol} \mathrm{mg}^{-1}\right)$.

This comparative experiment confirmed not only the viability of probe $\mathbf{1}$ for quantitative gold analysis, but also the ineffectiveness of silica gel and Celite in removing gold residues from crude products. On the other hand, purification through a pad of $\mathrm{Al}_{2} \mathrm{O}_{3}$ (basic) was highly efficient in removing gold impurities from the crude product. ${ }^{6} f$

Relying on the promising properties of probe $\mathbf{1}$, we next questioned whether probe $\mathbf{1}$ could be used for monitoring the
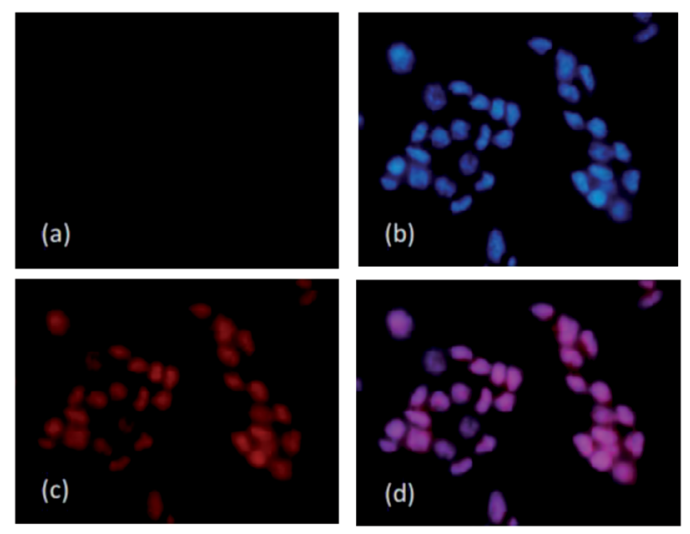

Fig. 3 Images of HCT-116 cells: (a) fluorescence image of HCT-116 cells treated with probe $1(20 \mu \mathrm{M})$ in the absence of $\mathrm{Au}^{3+}$ (control); (b) fluorescence image of HCT-116 cells treated with Hoechst-34580 (2 $\mu \mathrm{M})$ (control); (c) fluorescence image of HCT-116 cells treated with $\mathrm{Au}^{3+}(10 \mu \mathrm{M})$ and probe $1(20 \mu \mathrm{M})$; (d) merge image of frames $b$ and $c$.

accumulation of gold ions in living cells. Human colon carcinoma cells (HCT-116) were incubated with probe $1(20 \mu \mathrm{M})$ for $30 \mathrm{~min}$, followed by the addition of $\mathrm{Au}^{3+}$ and incubation for another $30 \mathrm{~min}$. The fluorescence images were recorded before and after the addition of $\mathrm{Au}^{3+}(10 \mu \mathrm{M})$ (Fig. 3). HCT-116 cells incubated with probe $\mathbf{1}$ exhibited no fluorescence, whereas a bright fluorescence signal was observed in the cells stained with probe $\mathbf{1}$ and $\mathrm{Au}^{3+}$, which suggested that probe $\mathbf{1}$ is cell membrane permeable and can be efficiently used for in vitro imaging of gold ions in living cells. Moreover, there were no indications of cell damage. Cells were intact and showed healthy spread and adherent morphology during and after the labeling process with probe $\mathbf{1}$, indicating an absence of cytotoxic effects.

In conclusion, we have developed a highly sensitive "turnon" type fluorescent probe that allows the naked eye detection of gold ions in various environments. The probe exhibits large fluorescence enhancement, high selectivity and a low detection limit. Furthermore, probe $\mathbf{1}$ was successfully employed for the quantitative determination of the concentration of $\mathrm{Au}^{3+}$ residues in synthetic samples. In addition, we have demonstrated the applicability of probe $\mathbf{1}$ to imaging gold ions in living cells.

The authors gratefully acknowledge İmir Institute of Technology (IZTECH) for financial support and Biological Mass Spectrometry and Proteomics Facility (IZTECH) for mass spectroscopy analysis.

\section{Notes and references}

1 For some reviews, see: (a) Z. Li, C. Brouwer and C. He, Chem. Rev., 2008, 108, 3239; (b) A. Arcadi, Chem. Rev., 2008, 108, 3266; (c) A. S. K. Hashmi and M. Rudolph, Chem. Soc. Rev., 2008, 37, 1766; (d) N. Krause and C. Winter, Chem. Rev., 2011, 111, 1994.

2 For some reviews, see: (a) C. F. Shaw, Chem. Rev., 1999, 99, 2589; (b) I. Ott, Coord. Chem. Rev., 2009, 253, 1670; (c) M. Navarro, Coord. Chem. Rev., 2009, 253, 1619. 
3 C. K. Kim, P. Ghosh and V. M. Rotello, Nanoscale, 2009, 1, 61.

4 (a) C. M. Goodman, C. D. McCusker, T. Yilmaz and V. M. Rotello, Bioconjugate Chem., 2004, 15, 897; (b) A. Habib and M. Tabata, J. Inorg. Biochem., 2004, 98, 1696.

5 For recent reviews, see: (a) M. E. Jun, B. Roy and K. H. Ahn, Chem. Commun., 2011, 47, 7583; (b) X. Chen, T. Pradhan, F. Wang, J. S. Kim and J. Yoon, Chem. Rev., 2012, 112, 1910.

6 (a) J. H. Do, H. N. Kim, J. Yoon, J. S. Kim and H. J. Kim, Org. Lett., 2010, 12, 932; (b) M. J. Jou, X. Chen, K. M. K. Swamy, H. N. Kim, H. J. Kim, S. G. Lee and J. Yoon, Chem. Commun., 2009, 7218; (c) O. A. Egorova, H. Seo, A. Chatterjee and K. H. Ahn, Org. Lett., 2010, 12, 401; (d) Y. K. Yang, S. Lee and J. Tae, Org. Lett., 2009, 11, 5610; (e) M. Dong, Y. W. Wang and Y. Peng, Org. Lett., 2010, 12, 5310; $(f)$ L. Yuan, W. Lin, Y. Yang and J. Song, Chem. Commun., 2011, 47, 4703.
7 (a) H. Seo, M. E. Jun, O. A. Egorova, K. H. Lee, K. T. Kim and K. H. Ahn, Org. Lett., 2012, 14, 5062; (b) N. Y. Patil, V. S. Shinde, M. S. Thakare, P. H. Kumar, P. R. Bangal, A. K. Barui and C. R. Patra, Chem. Commun., 2012, 48, 11229. 8 J. B. Wang, Q. Q. Wu, Y. Z. Min, Y. Z. Liu and Q. H. Song, Chem. Commun., 2012, 48, 744.

9 J. E. Park, M. G. Choi and S. K. Chang, Inorg. Chem., 2012, 51, 2880.

10 See ESI. $\dagger$

11 Y. Xiang, A. Tong, P. Jin and Y. Ju, Org. Lett., 2006, 8, 2863. 12 (a) Q. Ding, C. Zhiyuan, Y. Xingxin, W. Jie, D. Qiuping and P. Yiyuan, Tetrahedron Lett., 2009, 50, 340; (b) V. A. Peshkov, O. P. Pereshivko, S. Vanhove, D. S. Ermolatev and E. V. Vandereycken, Synthesis, 2011, 3371.

13 A. S. K. Hashmi, J. P. Weyrauch, W. Frey and J. W. Bats, Org. Lett., 2004, 6, 4391. 